\title{
Articulações entre \\ Ciberacontecimentos e Publicidade em Redes Digitais
}

Christian Gonzatti ${ }^{1}$

\section{Resumo}

$\mathrm{O}$ artigo pretende analisar as dinâmicas publicitárias que perpassam as lógicas de emergência dos ciberacontecimentos. Através de múltiplos casos, percebe-se que os acontecimentos tramados em redes digitais podem se configurar como possibilidade para o espalhamento de anúncios de marcas/empresas, assim como a visibilidade desses anúncios também pode motorizar a emergência de acontecimentos. Essas processualidades estão inscritas em um cenário complexo, no qual os consumidores/públicos podem reconfigurar a visibilidade e a imagem de instituições mercadológicas.

Palavras-chave: ciberacontecimento; redes digitais; mídias sociais; publicidade e propaganda; espalhamento.

\begin{abstract}
The article intends to analyze the advertising dynamics that go through the logic of emergence of cyberevents. Through multiple cases, it can be seen that events woven in digital networks can be configured as a possibility for spreading ads of brands/companies, as well as the visibility of these ads can also drive the emergence of cyberevents. These processes are embedded in a complex scenario in which consumers/public can reconfigure the visibility and image of market institutions.
\end{abstract}

Keywords: cyberevents; social networks; social media; advertising; spreadable.

\section{Introdução}

Nas pesquisas desenvolvidas no LIC, Laboratório de Investigação do Ciberacontecimento, do PPGCCOM da Unisinos, coordenado pelo Prof. Dr. Ronaldo Henn, notou-se que muitos casos investigados sinalizavam implicações múltiplas e complexas entre acontecimentos tramados através das dinâmicas digitais e ações que

1 Doutorando em Ciências da Comunicação. Mestre em Ciências da Comunicação e graduado em Comunicação Social com habilitação em Publicidade e Propaganda pela UNISINOS-

Universidade do Vale do Rio dos Sinos. christiangonzatti@gmail.com 


\section{VOZES $_{\text {\&IÁLORO }}^{\mid}$}

Itajaí, v. 17, n. 02, jul./dez. 2018

remetem à publicidade e propaganda. $\mathrm{O}$ artigo tem como objetivo, portanto, apontar as possibilidades de articulações entre ciberacontecimentos (HENN, 2014) e ações mercadológicas que visam o desenvolvimento de visibilidade e conversações em rede (RECUERO, 2014) por marcas/empresas. A primeira parte foca em problematizar o entendimento de redes digitais que tem-se aqui, a segunda tem como prioridade o tensionamento do conceito de ciberacontecimento para, assim, chegar ao objetivo colocado aqui através de múltiplos casos. Entende-se que a metodologia empregada nos processos do LIC - a análise de construção de sentidos em redes digitais (HENN, GONZATTI, ESMITIZ, 2017) - apresenta potências mercadológicas e acadêmicas para entender processos em rede através de múltiplas perspectivas.

\section{Redes Digitais}

As redes digitais ${ }^{2}$ se constituem em plataformas para cibersociabilidades. Nelas, aparecem o exercício das conexões e seus desdobramentos como, por exemplo, o espalhamento, que tem seu exercício efetivado através de ferramentas e aspectos culturais que tornam mais fácil a circulação de algum material (JENKINS, FORD, GREEN 2014). Em tais redes, “[...] não há como separar o que vem do humano e o que vem das plataformas, tudo se mistura: aparatos técnicos, sistemas de codificação, discursos, linguagens multimídia, percepções e afetos”. (SANTAELLA, 2013, p. 124). Por isso, as construções identitárias que emergem nesse contexto permitem uma constante atualização do "eu", encorajada pelos dispositivos destas plataformas. Assim, "ao criar um perfil nas redes sociais, as pessoas passam a responder e a atuar como se esse perfil fosse uma extensão sua, uma presença extra daquilo que constitui sua identidade”. (SANTAELLA, 2013, p. 115). Estas construções ocorrem, principalmente, através de imagens que são, constantemente, atualizadas através dos sites.

O Facebook, o Twitter e o Instagram, principalmente, aparecem como espaço de rastros destas sociabilidades imagética e de conversações em rede (RECUERO, 2014). Conceitos como competição, cooperação, popularidade e visibilidade ganham espaço nestes sites (RECUERO, 2009), por isso, "as dinâmicas impostas para o uso de uma rede social estimulam o usuário a externar suas predileções, favoritismos, preferências e interesses mais pessoais, favorecendo a afirmação e a publicização dos gostos e hábitos mais íntimos" (SOUZA E SILVA, 2014, p. 66). Nesse sentido, as redes digitais podem atuar como mídias sociais, favorecendo a divulgação dos atores sociais e suas conexões (RECUERO, BASTOS, ZAGO, 2015).

2Embora a terminologia "sites de redes sociais" seja utilizada por muitas pesquisas citadas, no trabalho, entende-se que os termos redes digitais, redes sociais digitais e redes sociais, também referem-se as mesmas especificidades que pretende-se tratar aqui. 


\section{VOZES \\ DIÁlOGO}

Itajaí, v. 17, n. 02, jul./dez. 2018

Estas publicizações do eu estimulam a transformação de situações corriqueiras em espetáculo (ESPÍNDOLA, 2013, p. 31). Através da atualização de status, as redes passam, por exemplo, a construir um movimento híbrido com produtos de entretenimento, aqui também vistos como arte ${ }^{3}$ e conteúdos com visibilidade. Marcas, nesses engendramentos, passam a atuar como pessoas e a desenvolver conversações mais humanas, fluídas e divertidas (SANTOS, 2015). Por exemplo, a personagem Nazaré Tedesco, da novela Senhora do Destino, exibida em junho de 2004 no horário das $21 \mathrm{~h}$, fez com que emergissem linguagens que impulsionam a interação nas redes digitais através de páginas criadas por fãs ${ }^{4}$ no Facebook. A Rede Globo, atenta a esses movimentos, anunciou a reprise da novela utilizando os signos constituídos em rede em torno da personagem ${ }^{5}$. Como consequência do seu uso em rede, Nazaré manteve a sua visibilidade ao longo dos anos, tendo sido usada, recentemente, para promover o filme Assassinato no Expresso do Oriente $^{6}$ (filme estadunidense dirigido por Kenneth Branagh e lançado em novembro de 2017).

Conforme Santaella (2013, p. 127), "Não há mais separação entre viver e narrar a vida enquanto ela passa”. Estas narrativas, junto com as construções das identidades e com as conversações que são desenvolvidas em rede, são responsáveis por uma crise nas fronteiras jornalísticas e nas formas como as lógicas do mercado estão lidando com estas transformações. Emerge, nesse contexto, uma nova forma de acontecimento, em que os sentidos nas redes digitais geram discussões e mobilizações que se engendram através da convergência (JENKINS, 2008) e do espalhamento (JENKINS, FORD, GREEN, 2014): o ciberacontecimento (HENN, 2014).

\section{Ciberacontecimentos}

Ao pensar na explosão de sentido e nas estruturalidades geradas pelos processos em redes digitais, Henn (2014) postula uma modalidade de acontecer que já tem como natureza própria a cultura digital: o ciberacontecimento. Tais acontecimentos se instituem através de dinâmicas de semiose e com potencial de gerar crise em fronteiras semiosféricas.

\footnotetext{
3Em concordância com o que aponta Janotti (2009, p. 6): "Reconhecer o valor estético de produtos de entretenimento é algo vital para o atual ambiente cultural que habitamos, mas descartar as estratégias mercadológicas que configuram características vitais desses produtos é negar a própria importância dos produtores culturais na cultura e comunicação contemporâneas. Não há mais espaço para que continuemos a valorar negativamente o mercado cultural, como se ainda idealizássemos uma esfera autônoma da arte". 4Página fictícia criada por fãs sobre a personagem: https://www.facebook.com/OficialNazareTedesco Acesso: 27 fev. 2018. 5 Fonte: http://www.papelpop.com/2017/03/globo-usa-meme-da-nazare-confusa-pra-avisarque-raposa-felpulda-esta-de-volta/. Acesso: 27 fev. 2018. 6 Fonte: http://www.ofuxico.com.br/noticias-sobre-famosos/renata-sorrah-aparece-emdivulgacao-de-filme-como-nazare-tedesco/2017/11/23-308110.html. Acesso: 27 fev. 2018.
} 


\section{VOZES $_{\text {\&IÁLORO }}^{\mid}$}

Itajaí, v. 17, n. 02, jul./dez. 2018

A intensa produção de sentidos nas redes digitais pode ser entendida como semiose. Para Peirce (2002), todo signo está vinculado a um objeto através de uma determinação lógica: o signo existe em função da sua capacidade de representar, apontar ou sugerir tal objeto, que o determina. O objeto pode ser sentimento, expressões, algo imaginado ou não verbalmente expressado - não precisa ser, necessariamente, dotado de uma materialidade física. $\mathrm{O}$ signo se completa quando gera um interpretante, que pode ser compreendido como um outro signo que está vinculado a um mesmo objeto. $\mathrm{O}$ interpretante gerado, desencadeia outros signos em cadeia consecutiva, gerando um processo de potência infinita. Esse movimento de ação, geração e propagação de signos pode ser compreendido como semiose. $\mathrm{O}$ acontecimento concentra em si a força propulsora da semiose: surge como signo e ao emergir desprega infinitas possibilidades de desvendamento do objeto que encarna. Henn (2014) recorre a essa noção para sinalizar que o processo de produção de sentidos em redes digitais pode ser compreendido como semiose e, devido a sua intensidade, gerar ciberacontecimentos.

Os ciberacontecimentos são, portanto, a transformação destes sentidos, desenvolvidos dentro das redes sociais digitais, em acontecimento. Esta modalidade de acontecer iniciou nos anos 1990, através do escândalo envolvendo o ex-presidente dos Estados Unidos, Bill Clinton, e a então estagiária da Casa Branca, Mônica Lewinski. O gerente de uma loja de conveniência no edifício da rede de televisão norte-americana CBS deu forma inicial ao acontecimento postando no seu blog, o The DrugeReport, o conteúdo das conversas telefônicas gravadas pela amiga e denunciante de Lewinsky, Linda Tripp (HENN, 2014).

Segundo Quéré (2005), o acontecimento é singularidade e ruptura, a partir dele sentidos se constroem desde que são capturados no campo da experiência. Assim, as redes digitais tornam-se determinantes para que os ciberacontecimentos desenvolvam as suas forças propulsoras de semioses. Para Lotman (1996), a semiosfera é o espaço de convergência e metabolização de todas as semioses, ou seja, dos processos que produzem sentido na realidade. Assim, cada ciberacontecimento é uma singularidade, algo único, com suas próprias características e que a partir de reconfigurações movimentam tensões na semiosfera, inaugurando um processo de sentido em que os signos geram variadas interpretações, criando um campo problemático. (HENN, 2014). Tendo em vista que os ciberacontecimentos colocam em evidência os processos narrativos das redes digitais, sinalizando transformações em práticas, procedimentos e rotinas mercadológicas, o próximo item é destinado a problematizar, a partir de múltiplos casos analisados no LIC, como a publicidade de diferentes marcas apropriam-se de ciberacontecimentos para desenvolver visibilidade e conversações em rede com os seus públicos. 


\section{Publicidade e ciberacontecimentos no contexto digital}

Toma-se aqui a publicidade e a propaganda como termos ambíguos e flexíveis atrelados ao marketing. Com a profissão publicitário no Brasil, é complexo definir barreiras conceituais entre a publicidade e a propaganda (LUPETTI, 2009). Mais importante do que a discussão terminológica entre publicidade e propaganda, desenvolvida por autores como Kotler, Kartajaya, Setiawan (2010) e Lupetti (2009), é entender como as novas linguagens interferem na construção de anúncios e ações de venda com o consumidor nas redes digitais. As mensagens publicitárias utilizam muito mais do que palavras para persuadir: imagens e estetização da mensagem aparecem como ferramenta para torná-las confiáveis. As semioses desenvolvidas em redes digitais abrangem, também, a publicidade e a propaganda através de estratégias de produção de conteúdo e planejamento.

A Nova York repleta de anúncios e propaganda está presente em todos os lugares das redes digitais através das plataformas de comunicação, em constante reconfiguração. McLuhan (2007, p. 255) já postulava que "a pressão contínua é a de criar anúncios cada vez mais à imagem dos motivos e desejos do público”. Assim, os consumidores desenvolvem uma nova relação com o mercado anunciante através das transformações decorrentes da cibersociabilidade.

Nestas novas cibersociabilidades, os consumidores "buscam não apenas satisfação funcional e emocional, mas também satisfação espiritual, nos produtos e serviços que escolhem”. (KOTLER, KARTAJAYA, SETIAWAN, 2010, p. 4). E o escolher, hoje, surge de uma relação que vai muito além de uma relação dicotômica entre anunciante e público-alvo. A ampliação das redes digitais torna, portanto, mais profícuo a possibilidade das pessoas conversarem sobre empresas, produtos e marcas, por isso, mercadologicamente, a ascensão das mídias sociais também é reflexo de novas configurações culturais. Você confia mais no que as suas conexões indicam - a publicidade entre consumidores ganha maior peso.

Com estas cibersociabilidades, propulsoras de semioses, desenvolvidas nas redes digitais, entra em ruptura o modelo em que a publicidade planejava e prescrevia como o ser humano deve ser, influenciando arregimentação de comportamentos. A discussão em torno do posicionamento das marcas ganha novos contornos através das plataformas de interação, criando um ambiente em que o consumidor pode discutir, compartilhar ou indicar determinado signo/produto. O grande desafio das empresas, anunciantes, estúdios, distribuidores de filmes e música, editoras, jornais, revistas passa a ser, como diz Gitlin (2003), o rompimento da "bagunça”. "Bagunça” é, para o autor, a pluralidade intensa de imagens e sons que surgem do frenesi da competição.

A busca por espaços que possibilitem este rompimento da bagunça para os anunciantes é uma das forças desenvolvidas pelas marcas nas redes digitais, em que se cria uma relação que consiga desenvolver o desejo no ser humano. As plataformas, como o 


\section{VOZES $_{\text {\&IÁLORO }}^{\mid}$}

Itajaí, v. 17, n. 02, jul./dez. 2018

Facebook e o Twitter, permitem o desenvolvimento de relacionamento com os consumidores através de anúncios que se validam através de promoções e impulsionamentos pagos, no entanto, o meio que permite "romper a bagunça" é a própria cibersociabilidade que emerge quando uma marca consegue cooptar uma imagem mais "humana”, motorizando as conversações e o espalhamento do seu conteúdo pelos públicos. Assim, os ciberacontecimentos surgem como forças propulsoras de semioses (HENN, 2014) que se articulam com a publicidade e a propagandas nas redes digitais.

O atual cenário mercadológico passou por diversas reestruturações com a ascensão da cultura digital na sociedade. Das pequenas às grandes empresas, conquistar espaços que garantam visibilidade em torno de determinado produto tem se tornado uma tarefa cada vez mais séria e complexa, do planejamento à mensagem que será veiculada. Os textos de mídia devem ir além do que era comum até o início do século 21 , pois não só pessoas desenvolvem sociabilidades em sites de redes digitais. "As empresas também devem interagir nestas plataformas, como forma de aproximar-se de seus públicos, sejam eles internos ou externos" (ESPÍNDOLA, 2013, p. 18). Para esse movimento, o caráter de mídia social e espalhável das redes digitais torna-se imprescindível.

Tendo em vista que "a produção do desejo, produção de realidade, é ao mesmo tempo (e indissociavelmente) material, semiótica e social” (ROLNIK, 2014, p.46), não se pode negar as linguagens que emergem na web como forma de desenvolvimento de cibersociabilidade entre as marcas e seus públicos. Em poucas palavras, as empresas desenvolvem conteúdos com mais chances de serem espalhados por perfis ou de gerarem conversações entre as marcas e os públicos (JENKINS, FORD, GREEN, 2014).

Assim como nos primórdios da publicidade os anúncios apenas informavam sobre como os produtos deveriam ser usados e seu preço, atualmente, eles devem cumprir a tarefa de engajar os públicos em práticas de compartilhamento que buscam estender as identidades digitais e criar ligações emocionais com os públicos. Os ciberacontecimentos surgem, então, como meio de tentativas para desenvolver visibilidade e capital social através do espalhamento por atores sociais.

As propagandas estão se tornando mais lúdicas e participativas, e não contam mais com sua capacidade de exigir atenção perturbando as práticas que escolhemos como entretenimento. Pelo contrário, os anunciantes se esforçando para criar textos que as pessoas busquem ativamente e circulem de bom grado (JENKINS, FORD, GREEN, 2014, p. 280).

Assim, do conjunto de casos analisados nas pesquisas do LIC, inferiu-se ciberacontecimentos em torno de mobilizações globais, protestos virtuais, exercícios de cidadania, afirmações culturais, entretenimentos e subjetividades, tendo em vista que cada um desses englobamentos possui especificidades marcantes, tanto do ponto de vista da sua constituição, como das narrativas que geram, mas que se contaminam (HENN, 2014). Na 


\section{VOZES:}

Itajaí, v. 17, n. 02, jul./dez. 2018

coleta de dados em torno destes ciberacontecimentos, para posterior análise de construção de sentidos em redes digitais, metodologia do grupo, o autor, através do mergulho nos sites de redes sociais, construiu um corpus que não se encontra completamente nas delimitações deste artigo. Trabalha-se, aqui, com um recorte desses dados que demonstra empiricamente algumas especificidades das articulações. entre ciberacontecimentos e publicidade e propaganda.

A metodologia denominada como análise de construção de sentidos em redes digitais (HENN, GONZATTI, ESMTITIZ, 2017) tem como pressuposto três movimentos: o mapeamento, o agrupamento de constelações de sentidos e a elaboração de inferências sobre o movimento. Logo, as pesquisas do grupo sobre ciberacontecimentos exigiam movimentos cartográficos diários em plataformas como o Twitter e o Facebook, visando entender como se davam a emergência de acontecimentos tramados nas redes digitais e os processos de semiose acionados pelo mesmo. $\mathrm{O}$ corpus de cada caso era armazenado em pastas de um drive para, posteriormente, passar pelo processo que leva à elaboração de constelações de sentidos. Aqui, no entanto, o foco é trazer alguns exemplos emblemáticos recortados da sua fase de mapeamento para refletir sobre a articulação entre ciberacontecimentos e publicidade e propaganda.

Um dos primeiros casos em que o movimento foi notado nas pesquisas do grupo, foi em novembro de 2013. O vídeo Os dez mandamentos do Rei do Camarote inaugurou apropriações e, consequentemente, semioses desenvolvidas por atores sociais, resultando, assim, em pautas jornalísticas. Uma análise do caso foi desenvolvida por Henn e Kolinski Machado (2014). Aqui, é importante o destaque de algumas apropriações publicitárias em torno do caso, exemplificadas pelas imagens abaixo.

7 Disponível em: https://www.youtube.com/watch?v=atQvZ-nqOGo. Acesso: 21 set. 2015. 


\section{VOZES $_{\text {\&IÁLOGO }}$}

Itajaí, v. 17, n. 02, jul./dez. 2018

Figura 1 - O Rei do Camarote
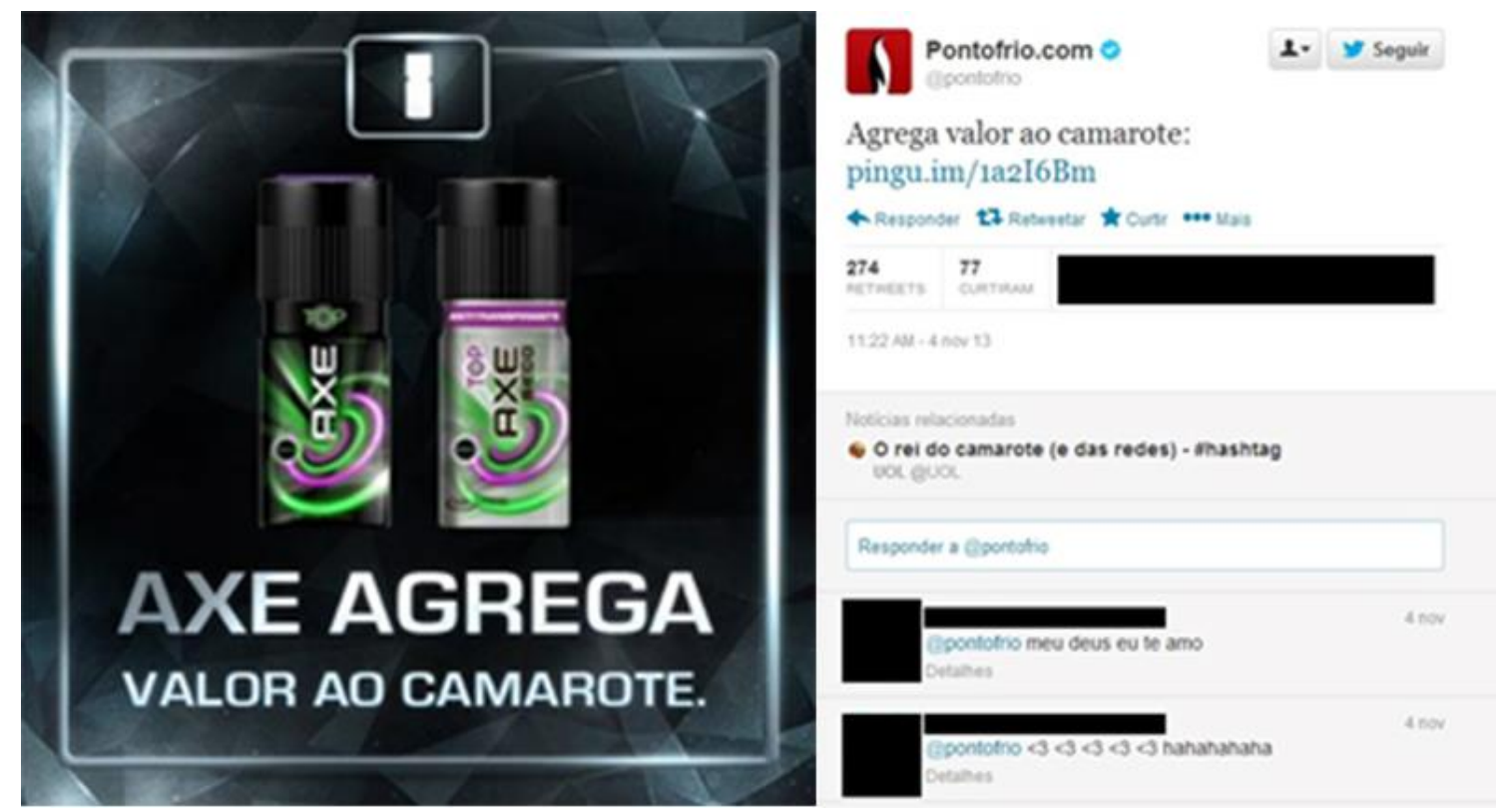

Fonte: Coleta de dados realizada pelo autor.

As publicações da figura 1 fazem referência a uma das falas do "Rei do Camarote". Em um vídeo produzido pela Veja, o empresário Alexander Augusto de Almeida apresenta uma série de mandamentos que fariam parte da performance de uma pessoa que frequenta camarotes. Assim, existem diversos elementos que são apontados como agregadores de valor ao camarote. $\mathrm{O}$ caso gerou uma intensidade semiótica na rede, inaugurando campos problemáticos (QUÉRÉ, 2005) e se constituindo como um ciberacontecimento. Como aponta Espíndola (2013, p. 20), “[...] o significado essencial que as marcas assumem para os consumidores pode mudar suas percepções e experiências com um produto”. Assim, marcas começaram a aproveitar o fluxo de visibilidade do ciberacontecimento para desenvolverem publicações que não só anunciam o produto, mas também visam o espalhamento e a construção de conversações - relacionamento - com os públicos. No caso do Ponto Frio, por exemplo, as semioses inauguradas demonstram a forma como o público passa a desenvolver sociabilidade com a marca no Twitter. Estas singularidades não são exclusividade de apenas uma forma publicitária desenvolvida na rede. Em uma linha temporal, outros casos passaram a demonstrar as mesmas características.

Em formas imagéticas ou textuais, o ciberacontecimento, no seu ápice de visibilidade, passa a ser integrado a anúncios publicitários, concordando com o modelo de Jenkins, Ford e Green (2014) de espalhabilidade. Atores sociais que acompanham as marcas nas redes digitais passam a agir como fãs espalhando o conteúdo na rede, criando, assim, uma arquitetura de participação entre o mercado, a cultura e a sociedade. Outros casos, exemplificados na imagem a seguir, apontam para esta matriz mercadológica que 


\section{VOZES $_{\text {\&DÁLOGO }}^{\mid}$}

Itajaí, v. 17, n. 02, jul./dez. 2018

surge da força propulsora de sentidos que inaugura (e é inaugurada por) ciberacontecimentos.

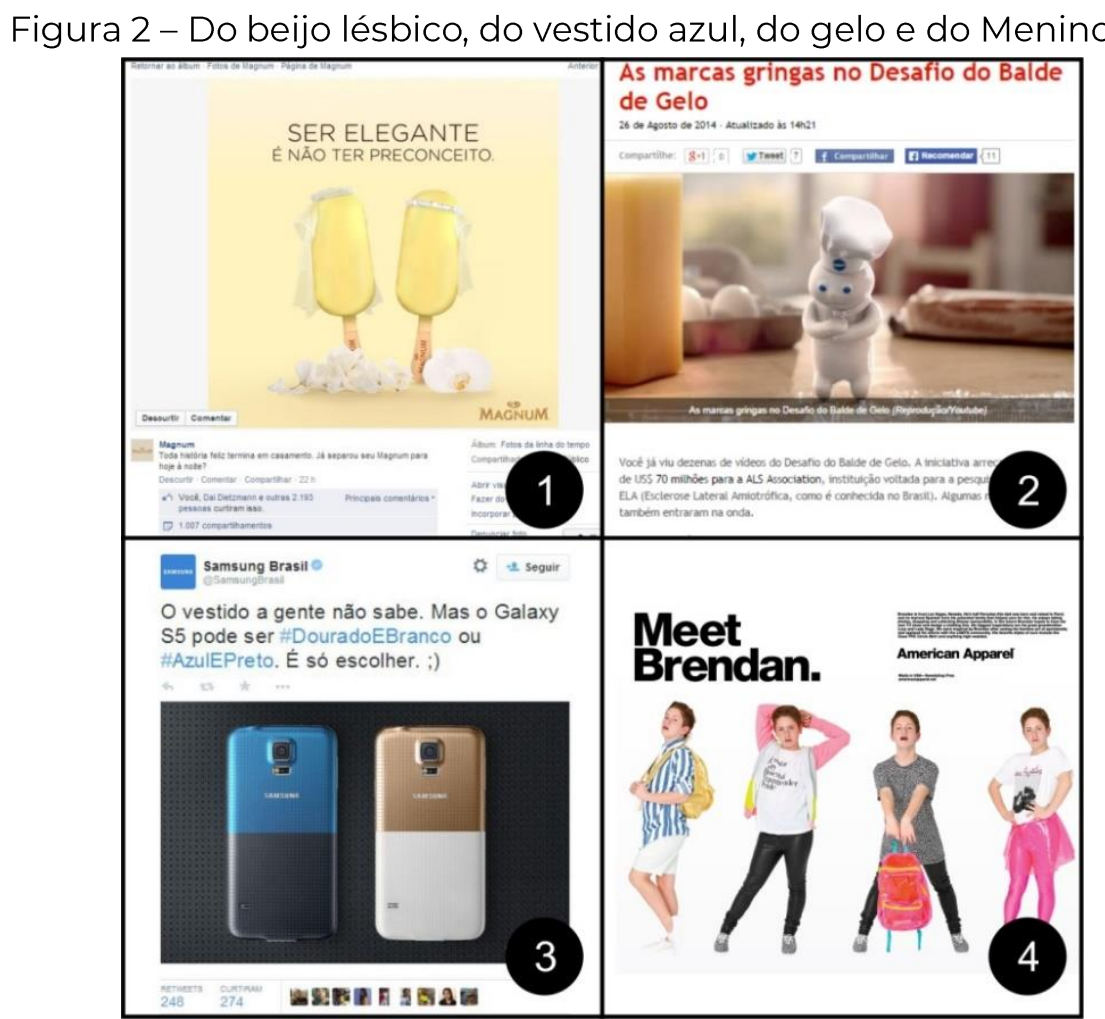

Fonte: Coleta de dados realizada pelo autor.

Como demonstrado na figura 2, as marcas buscam, através de estratégias de linguagem, desenvolver conteúdos publicitários que acionem semioses a um nível que permita a ruptura com modelos mercadológicos postos e o estabelecimento de proximidade com os públicos. No quadro número 1, a marca apropria-se da polêmica em torno do beijo lésbico (seguindo um movimento semelhante já inaugurado pelo beijo gay entre Félix e Niko, na novela exibida anteriormente) na telenovela das 21h, Em Família, que inaugurou uma série de debates em torno dos gêneros e das sexualidades nas redes digitais que se constituíram como ciberacontecimentos (HENN, KOLINSKI MACHADO, 2015). Assim como o caso do menino Brendan Jordan, que se tornou uma webcelebridade (CORNUTTI, 2015) após dançar em frente às câmeras de um jornal local, na inauguração de um shopping em Las Vegas, a coreografia de Applause, música de Lady Gaga; o vídeo foi espalhado pelas redes digitais tornando-se um ciberacontecimento, assim, a marca de moda American Apparel apropriou-se da visibilidade do acontecimento e, ao mesmo tempo, criar um espaço para a transgressão de normas de gênero (HENN, GONZATTI, VIERO, 2016). 


\section{VOZES $_{\text {\&IÁLORO }}^{\mid}$}

Itajaí, v. 17, n. 02, jul./dez. 2018

As constatações de Jenkins, Ford e Green (2014) de que nada é gratuito, sempre há uma troca social implicada, mobilizam a reflexão de como o entretenimento, com toda a sua fruição de sentidos (JANOTTI JR., 2009), surge como valor para que atores sociais espalhem conteúdos, criando novos textos de mídia e compartilhando os já desenvolvidos. Assim como os quadros 1 e 2, os exemplos da figura 2, demonstrados nos quadros número 2 e 3, que trazem, respectivamente, as apropriações de marcas estrangeiras em torno do Desafio do Balde de Gelo (AQUINO BITTENCOURT et al, 2014) - que, inclusive, inaugura um novo nível de ciberacontecimento em torno do caso, em que a publicidade é motor da pauta jornalística - e o anúncio da Samsung sobre a polêmica inaugurada pela discussão da cor de um vestido ${ }^{8}$ também são pertencentes ao campo do entretenimento.

O entretenimento, a cultura da diversão, o pop, o espetáculo, surgem como base de muitos ciberacontecimentos que foram apropriados para ações publicitárias de marcas em redes digitais. Casos emblemáticos dessa relação, são os anúncios da empresa de streaming Netflix. Como exemplo, sinaliza-se as ações publicitárias específicas da série Stranger Things (criada pelos irmãos Matt e Ross Duffer e distribuída pela Netflix) que tiveram como protagonista a atriz, cantora e apresentadora Xuxa Meneghel ${ }^{9}$. Os vídeos publicitários $O$ maior mistério dos anos $80^{\circ}$ e Xuxa e o baixinho que sumiu ${ }^{\prime \prime}$, a utilizarem linguagens meméticas construídas em redes digitais em torno de Xuxa, obtiveram uma popularidade e espalhamento com a potência para ganharem a atenção de, inclusive, veículos jornalísticos, tornando-se um ciberacontecimento. É um caso de articulação inversa: a ação publicitária deflagra um ciberacontecimento e não o contrário, como nos casos já citados. Movimentos semelhantes apareceram, também, no caso da selfie do Oscar no ano de 2014, publicada no perfil do Twitter da apresentadora Ellen Degeneres, obtendo recordes de compartilhamento. Depois, descobriu-se que o uso e a publicação de fotos da cerimônia em seu perfil era uma ação publicitária da Samsung (GONZATTI, 2015). Outro ato que também seguiu a lógica de se configurar como uma ação publicitária capaz de desencadear um ciberacontecimento, foi a publicação de um vídeo publicitário de Dia dos Namorados da marca O Boticário (ESMITIZ, 2016). Por ter casais supostamente gays e lésbicos, a ação gerou uma série de disputa de sentidos em redes digitais: pessoas defendendo a diversidade retratada, outras pedindo mais diversidade, manifestações de

\footnotetext{
8Para mais informações: http://www.msn.com/pt-br/entretenimento/galeria/dourado-ou-azulvestido-da-disc\%C3\%B3rdia-cria-pol\%C3\%AAmica-e-vira-meme-nas-redes-sociais/ss-BBizezf. Acesso: 28 fev. 2017

9 Maria da Graça "Xuxa" Meneghel é uma apresentadora, atriz, cantora pop infantil, empresária, filantropa e modelo brasileira. Duas vezes vencedora do Grammy Latino de melhor álbum infantil, é conhecida também pelo epíteto de Rainha dos Baixinhos. Fonte: https://goo.gl/DPo8we Acesso: 28 fev. 2018. 10 Link para o vídeo: https://www.facebook.com/strangerthingsbr/videos/1393407097341682/ Acesso: 08 ago. 2016. 17 Link para o vídeo: https://www.facebook.com/strangerthingsbr/videos/1394199200595805/ Acesso: 08 ago. 2016.
} 


\section{VOZES $_{\text {\&IÁLORO }}^{\mid}$}

Itajaí, v. 17, n. 02, jul./dez. 2018

preconceito e ódio e uma intensa semiosfera que, ao final de sua reverberação, beneficiou a empresa anunciante, que teve um aumento das vendas naquele período.

Como sinalizado pelo caso de $O$ Boticário, nem sempre as articulações entre ciberacontecimentos e publicidade e propaganda são engendradas pelo entretenimento. Algumas vezes, ações publicitárias podem implicar em questões do campo da cidadania e do ciberativismo (MALINI, ANTOUN, 2013), trazendo resultados negativos para uma marca. Criada pela F/Nazca $S \& S$, uma agência de publicidade e propaganda, a campanha com a assinatura "Viva Redondo" - que, segundo a cervejaria, tinha como foco "aceitar os convites da vida e aproveitar os bons momentos" - expunha frases como "Esqueci o 'não' em casa" e "Topo antes de saber a pergunta". No dia 11 de fevereiro de 2015, a publicitária Pri Ferrari postou na sua página do Facebook fotos que registravam a intervenção feita por ela e sua amiga, a jornalista Mila Alves, em um mobiliário urbano que trazia a frase "Esqueci o 'não' em casa”. As amigas acrescentaram, com fita isolante, "e trouxe o nunca" ${ }^{12}$. Para a publicitária, a campanha passava uma mensagem que "induzia à perda de controle" e as violências de gênero. Ainda na postagem ela destaca que o índice de estupro aumenta durante o carnaval e encerra o discurso com as hashtags \#feminismo \#respeito e \# estuproNAO. Após a alta repercussão da publicação e a sua constituição como um ciberacontecimento (SCOPEL, 2016), a Ambev, companhia que produz a cerveja, entrou em contato com Pri Ferrari e emitiu um comunicado de esclarecimento destacando que repudia qualquer violência física e emocional e que, com o entendimento dúbio da mensagem, trocaria a comunicação das peças. O conteúdo foi substituído por mensagens como: "Quando um não quer, o outro vai dançar", "Tomou bota? Vai atrás. Do trio" e "Não deu jogo? Tire seu time de campo". No final dos novos anúncios, a assinatura: "Neste carnaval, respeite”. O episódio desencadeou uma transformação no posicionamento e nas ações em torno da marca ${ }^{13}$.

Existem, também, o caso em que movimentos com teor ciberativista deflagram ciberacontecimentos e, consequentemente, são apropriados por marcas visando o desenvolvimento de anúncios. Pilz (2017) demonstra essa relação através da apropriação publicitária dos ciberacontecimentos envolvendo a campanha feminista \#MeuAmigoSecreto e a performance em rede em torno da legalização do casamento LGBTQ - com marcas desenvolvendo anúncios que seguiam as lógicas dos perfis publicarem fotos com as cores do arco-íris.

12Fonte: http://i.imgur.com/cpixypz.jpg. Acesso: 28 fev. 2018. 13Fonte: http://www.meioemensagem.com.br/home/comunicacao/2017/03/09/skol-assumepassado-machista-e-ressalta-a-importancia-de-evoluir.html. Acesso: 28 fev. 2018. 


\section{VOZES: \\ ¿'DIÁLOGO}

Itajaí, v. 17, n. 02, jul./dez. 2018

\section{Considerações Finais}

Os ciberacontecimentos inauguram campos problemáticos que podem funcionar como meio para anúncios publicitários, podendo, também, emergirem através de movimentos da publicidade e propaganda malsucedidos ou de sucesso. No primeiro caso, podem exigir revisão de posicionamento e gastos para as empresas/marcas, enquanto no segundo, mobilizam um valor de mídia social. As pautas inauguradas em torno de um conteúdo potencializam a sua visibilidade e espalhamento. No caso da selfie do Oscar, por exemplo, o seu valor de mídia foi avaliado em mais de $\mathrm{R} \$ 2,2$ bilhões de reais ${ }^{14}$ As linguagens desenvolvidas nas redes digitais, integradas a muitos ciberacontecimentos, criam ambientes ricos em dados que permitem entender como podem ser construídas cibersociabilidades. Assim, a análise de construção de sentidos em redes digitais demonstra que publicitários podem desenvolver conteúdos eficazes, espalháveis e com maior potência de mobilizar conversação, assim como aponta para possibilidades de pesquisas que se desdobrem sobre os sentidos que são acionados nas articulações entre os ciberacontecimentos e a publicidade.

\section{Referências}

AQUINO BITTENCOURT, M.C (et al). O Desafio do Balde de Gelo como ciberacontecimento: celebridades como vetores-chave de espalhamento e apropriações. Revista Fronteiras, São Leopoldo, v.17, n.1, 2015.

CORNUTTI, C. Celebridades e apropriações humorísticas em blogs : uma análise do Morri de Sunga Branca e do Te Dou Um Dado?. Tese (Doutorado em Comunicação e Informação) - Faculdade de Biblioteconomia e Comunicação, UFRGS, Porto Alegre, 2015 .

ESMITIZ, F. Lágrimas da Família Tradicional: os sentidos inaugurados pela campanha de Dia dos Namorados da O Boticário. Trabalho de Conclusão do Curso de Publicidade e Propaganda, Unisinos, São Leopoldo, 2016.

ESPÍNDOLA, P. M. Textos e Contextos do Audiovisual na Comunicação. São Leopoldo, RS, UNISINOS, 2013.

GITLIN, T. Mídias sem limite. Rio de Janeiro: Civilização Brasileira, 2003.

GONZATTI, C. Ciberacontecimento feat. Publicidade e Propaganda: but first, let me take a selfie. Trabalho de Conclusão do Curso de Publicidade e Propaganda, Unisinos, São Leopoldo, 2015.

14 Fonte: http://wwwl.folha.uol.com.br/ilustrada/2014/04/1437851-selfie-do-oscar-vale-r-22-

bilhoes-diz-especialista-em-marketing.shtml. Acesso: 28 fev. 2018. 


\section{VOZES \\ DIÁLOGO \\ Itajaí, v. 17, n. 02, jul./dez. 2018}

Henn, R; GOnZATTI, C; ESMITIZ, F. Pussy Made of Steel: os sentidos inaugurados por um cartaz da Women's March na página Supergirl Brasil. Revista Fronteiras, Estudos Midiáticos. v. 19, n.3. Set/Dez. 2017.

HENN, R; GONZATTI, C; KOLINSKI MACHADO, F.V. Jordan lives for the applause: perfomances de si como propulsoras de ciberacontecimentos. In: Encontro Anual da Compós, 25., 2016, Goiânia. Anais... Goiânia: UFG, 2016.

HENN, R. El ciberacontecimiento: producción y semiosis. Barcelona: Editorial UOC, 2014.

HENN, R; KOLINSKI MACHADO, F V. Mas... e o beijo das travestis? de Feliko e Clarina, dos sentidos produzidos em rede e de quem pode (e como pode) beijar no horário nobre. Contemporanea, v. 3, n. 12, 2015. Disponível em: https://portalseer.ufba.br/index.php/contemporaneaposcom/article/view/13846. Acesso: 28 fev. 2018.

JANOTTI JR, J. Entretenimento, Produtos Midiáticos e Fruição Estética. In: XVIII Encontro da Associação Nacional de Programas de Pós-Graduação em Comunicação, Compós. Anais Eletrônicos. Belo Horizonte (MG), 2009.

JENKINS, H. Cultura da convergência. São Paulo: Aleph, 2008.

JENKINS, H; FORD, S.; GREEN, J. 2014. Cultura da Conexão: criando valor e significado por meio da mídia propagável. São Paulo: Aleph, 2014.

KOLINSKI MACHADO, F.V; HENN, R. And we'll never /wannal be royals: Do movimento dos sentidos sobre a realeza do camarote e sobre as bebidas que piscam. Anais do XII Congreso de la Asociación Latinoamericana de Investigadores de la Comunicación, realizado Perú/Lima, 2014.

KOTLER, P; KARTAJAYA, H; SETIAWAN, I. Marketing 3.0: as forças que estão definindo o novo marketing centrado no ser humano. $9^{\text {a }}$ reimpressão, Rio de Janeiro: Elsevier, 2010.

LOTMAN, Y. La semiosfera: semiótica de la cultura y del texto. Madri: Catedra, 1996.

LUPETTI, M. Gestão estratégica de comunicação mercadológica. $1^{\underline{a}}$ ed. São Paulo: Cergage Learning, 2009.

MALINI, F; ANTOUN, H. @internet e \#rua: ciberativismo e mobilização nas redes sociais. Editora Sulina: Porto Alegre, 2013.

MCLUHAN, M. Os meios de comunicação como extensão do homem. 15 reimpressão da $1^{\underline{a}}$ ed. São Paulo: Cultrix, 2007.

PEIRCE, C. S. The Collected Papers of Charles Sanders Peirce. Past Masters, CDROM. EUA, InteLex Corporation, 2002.

PILZ, J. Apropriações publicitárias de ciberacontecimentos: sentidos oriundos de conversações em rede operadas por atores sociais com interesses mercadológicos como estratégia de relacionamento. Dissertação de mestrado, Unisinos, São Leopoldo, 2017. 


\section{VOZES $_{\& \text { DIÁLORO }}^{\downarrow}$}

Itajaí, v. 17, n. 02, jul./dez. 2018

QUÉRÉ, L. Entre facto e sentido: a dualidade do acontecimento. Trajectos Revista de Comunicação, Cultura e Educação. Lisboa, nº 6, 2005, p. 59-76.

RECUERO, R. A conversação em rede. Comunicação mediada pelo computador e redes sociais na internet. $2^{\underline{a}}$ ed. Porto Alegre: Sulina, 2014.

RECUERO, R. Redes Sociais na Internet. 1. ed. Porto Alegre: Sulina, 2009.

RECUERO, R.; BASTOS, M.; ZAGO, G. Análise de redes para mídia social. Porto Alegre: Sulina, 2015.

ROLNIK, S. Cartografia sentimental: transformações contemporâneas do desejo. 2 $2^{\text {a }}$ edição: Porto Alegre, Sulina; Editora da UFRGS, 2014.

SANTAELLA, L. Comunicação ubíqua: repercussões na cultura e na educação. $1^{\underline{a}}$ ed. São Paulo: Paulus, 2013.

SANTOS, A. B. O self marcário: identidade, autoapresentação e gerenciamento de impressão de marcas em Sites de Redes Sociais. IN: RIBEIRO, José Carlos; BRAGA, Vitor; SOUSA; Paulo Victor (orgs.). Performances interacionais e mediações sociotécnicas. Salvador: EDUFBA, 2015.

SCOPEL, V. Esqueci o não em casa: os sentidos e as implicação do ciberacontecimento. Trabalho de Conclusão do Curso de Publicidade e Propaganda, Unisinos, São Leopoldo, 2016.

SHIRKY, C. A cultura da participação: criatividade e generosidade no mundo conectado. $1^{\text {a }}$ ed. Rio de Janeiro: Zahar, 2011.

SOUZA E SILVA, W. Imagem e subjetividade: narrativas fotográficas confessionais e a estética da afetividade. Ciberlegenda, Rio de Janeiro, n. 31, 2014. 